\title{
A Study on the Structural Response of a PSC Inner Containment Dome with Large Openings Due to Prestress Transfer
}

\author{
Anirudh A. Desai, Sekhar K. Chakrabarti \\ Department of Civil Engineering, Indian Institute of Technology, Kanpur, India \\ Email: chakra@iitk.ac.in \\ Received 1 December 2013; revised 17 January 2014; accepted 2 February 2014 \\ Copyright (C) 2014 by authors and Scientific Research Publishing Inc. \\ This work is licensed under the Creative Commons Attribution International License (CC BY). \\ http://creativecommons.org/licenses/by/4.0/

(c) (i) Open Access

\section{Abstract}

A linear three dimensional finite element (FE) study has been carried out to examine the structural response of a prestressed concrete (PSC) inner containment (IC) dome of reactor building (double containment system) of a typical Indian Nuclear Power Plant, having large steam generator (SG) openings with due emphasis on the local behaviour of the steel-concrete interfaces at the SG openings, due to initial prestress transfer. The predominant thrust of the study has been placed on the objective of predicting the possibilities of separation at the steel-concrete interface zones adjacent to the embedded plates (EPs) of the SG openings. Two types of modeling and analysis have been made to study the overall and local behaviour of the structure. Prestressing ducts, passive reinforcements and EPs have been included in the models in certain ways. For the FE analysis, the interface zone has been modeled using interface elements, the properties of which were derived from the results of past experiments conducted on steel plate-concrete inter-face specimens. The FE analysis results have been compared with the results of the past two FE analytical studies on the linear behaviour of the same PSC IC dome. Important observations have been made regarding dome deformation and stresses throughout the structure with special emphasis on the local behaviour of steel-concrete interfaces at and around the SG openings.

\section{Keywords}

Prestressed Concrete, Inner Containment, Reactor Building, Double Containment System, Steel-Concrete Interface, Steam Generator Openings, Steel Embedded Plates

\section{Introduction}

The structural arrangement of the reactor building of a typical Indian Pressurized Heavy Water Reactor (PHWR)

How to cite this paper: Desai, A.A. and Chakrabarti, S.K. (2014) A Study on the Structural Response of a PSC Inner Containment Dome with Large Openings Due to Prestress Transfer. World Journal of Nuclear Science and Technology, 4, 103122. http://dx.doi.org/10.4236/wjnst.2014.42016 
based Nuclear Power Plant (NPP) consists of two containments; inner (primary) and outer (secondary) [1]. Both the containment structures have vertical cylindrical wall and segmental spherical dome as cap and they rest on a common reinforced concrete base raft. The inner containment (IC) structure is made of prestressed concrete (PSC) while the outer containment (OC) is made of reinforced concrete (RC). Both the PSC IC dome and RC OC dome have major circular (in plan) openings, which are called steam generator (SG) openings, and are sealed with dished heads after erection of the SGs. These dished heads are connected to the dome concrete through steel embedded parts (EPs), which are provided as linear plates along the edges of the SG openings. The SG openings are the unique features of the containment structure of a PHWR based Indian NPP. However, it has become important to investigate the overall structural performance as well as the performance of the steel-concrete interfaces with respect to the separation that may occur in the IC dome due to the situations arising out of the initial prestress transfer and other associated details for the prestressing anchorages and the steel EPs at the openings. Though efforts are made to provide appropriate concrete along with prestressing steel, embedded steel and passive reinforcements, and all joints are sealed using specially developed methods. Any "weakness" at the steel-concrete interface at SG openings in the IC dome, may cause problems in the serviceability of the containment system. Required steps can possibly be taken at the design and construction stages to control leakages through individual components, e.g., embedded steel, concrete, system components, and sealing between embedded steel and system component. However, the phenomenon of leakage through the steel-concrete interface zone is not well understood and it is thought that possibility of leakage exists essentially through these interfaces at SG openings. In view of this, it is important to predict the performance of this interface in respect of separation that may occur during initial prestress transfer. It is to be appreciated here that once the construction is completed it becomes extremely difficult to implement any corrective schemes in case any leakage paths are identified in the interface zone.

The issue of leakage has been addressed by Chakrabarti et al. [2] [3] specifically for the case of steel-concrete interfaces at penetration assemblies of the SG openings in the IC dome of a typical Indian PHWR. The reduction of tensile strength of steel-concrete interface compared to the tensile strength of concrete was observed experimentally by Basu and Rajagopalan [4]. Chakrabarti and Basu [5] have dealt with the issues related to the performance of steel-concrete interfaces with respect to the separation that may occur in the PSC IC dome due to the situations arising out of prestressing cable and other associated details for the prestressing anchorages, steel EPs at the openings and passive reinforcements. The authors concluded that examination of leakage possibilities through the steel-concrete interface zones at and around SG openings in the PSC IC dome, should be regarded as one needed safety requirement to be met over strength and stability requirements. It was also opined that the knowledge about the local steel-concrete interface behaviour will be of help in designing the interface adequately against any possible separation. Chakrabarti et al. [6]-[8] conducted experimental studies on steel plateconcrete interface specimens. Plain high strength concrete specimens each with one embedded steel plate (without anchors) were tested in direct tension, direct shear and in combined shear and normal forces. Some important conclusions were made from these studies regarding the steel plate-concrete interface.

Murali Mohan et al. [9] carried out a FE study on the linear behaviour of the PSC IC dome (of the actual double containment reactor building of the typical 220 MWe capacity Indian NPP) having large SG openings under predominant design loading conditions. The primary thrust of the work has been on knowing the dome response at and around the openings. Linear elastic FE analysis of the entire structure (consisting of PSC cylindrical wall monolithically built on the base raft, PSC segmented spherical dome with four SG openings at the top of the PSC cylindrical wall, and PSC ring beam at the springing level of the dome) from its base (at the top of the base raft) to the full height including the SG openings, but only considering one of its symmetric halves, was performed. The FE analysis was done using 3-D general thick shell element and beam element. The vertical cylindrical steel EPs at the edges of the SG openings have been modeled using beam elements. The top surface EPs at the edges of the SG openings have not been modeled separately, but their effects have been accounted for by changing the Young's Modulus of the attached shell element equivalently. It is worth noting here that in this study, the FE models exclude passive steel reinforcements, prestressing details, exact details of EPs and steelconcrete interfaces. The authors concluded that the IC dome undergoes predominantly vertical displacement under dead load + prestress condition (at initial prestress transfer). They also concluded that the magnitude of maximum compressive principal stress in the IC dome is always within the elastic limit with significantly high tensile principal stress observed near the SG openings and at some specific locations along the circumference of the SG openings. 
Gandhi et al. [10] performed a FE analytical study on the linear behavior of the PSC IC dome (of the same actual containment structure as of the study by Murali Mohan et al., [9] having large SG openings with emphasis on the local behavior of the steel-concrete interfaces near the SG openings), under initial prestress transfer. The primary thrust of the work has been in the objective of predicting the possibilities of separation at the steel-concrete interfaces adjacent to the EPs of the SG openings of the IC dome, during initial prestress transfer. Only one of the two symmetric halves of the IC structure, from the top of the base raft to its full height including SG openings, has been modeled. 3-D isoparametric solid elements have been used for modeling IC wall, dome and ring beam. The steel EPs at the SG openings have been modeled using 3-D general shell elements. The steel lugs of the EPs have been modeled using bar elements. The interface zone between the EPs and the dome concrete has been modeled with GAP elements. In this study, the FE models do not include the passive reinforcements and prestressing details, but the models do include the steel-concrete interfaces with EPs (with lugs) at SG openings for studying the local behavior of the steel-concrete interfaces near the SG openings. The authors made important conclusions regarding dome deformation and the stresses with special emphasis on the local behavior of steel-concrete interfaces at SG openings.

As presented in the above, both the past two FE analytical studies [9] [10] are on the linear behavior of the PSC IC dome (with large SG openings) of the same actual double containment reactor building of the typical 220 MWe capacity Indian NPP, for the condition arising out of initial prestress transfer. The FE analytical work [11] that is reported in this paper also deals with the linear behavior of the same PSC IC dome for its condition under initial prestress transfer; but, this work is novel for its following important distinctive features:

- Layered shell modeling and analysis of the symmetric half of the IC structure from the top of the base raft to its full height including SG openings, passive reinforcements and prestressing ducts in a realistic way for studying the overall behavior of the structure.

- Solid element modeling and analysis of only the thickened region around the two SG openings (including the transition region) including prestressing ducts, steel EPs at SG openings, and steel-concrete interfaces at the SG openings.

In the context of the merit of this paper, it is to be noted that there are no other available research data regarding the important aspects of the structural behavior (both in the sense of overall structural behavior with due emphasis on the local behavior of the steel plate-concrete interfaces at the SG openings as well as at the pertinent locations of the IC domes for the condition arising out of dead load and initial prestress transfer) for this particular type of containment structure, than the ones referred here in this paper.

\section{Structural Arrangement of the Inner Containment}

The details regarding the different important components, prestressing, EPs and passive reinforcements etc. have been published elsewhere [10].

\section{Modeling and Analysis}

CSA/NASTRAN [12] a general purpose large-scale structural finite element analysis package has been used along with its graphical interface FEMAP [13], for executing the finite element analysis for the present study [11]. Following two types of modeling and analysis were made:

1) Layered shell modeling and analysis for studying the overall behavior of the structure; and

2) Solid element modeling and analysis for studying the local behavior of the structure at and around the SG openings.

One of the notable features of the present study is the inclusion of prestressing ducts in the models. In an attempt to achieve the computational economy, in the solid element modeling, the steel EPs at the SG openings and the prestressing ducts were included in the selected region of thickened portion with the transition zone; and the analysis of solid element model was made for the enforced boundary condition as obtained from the layered shell analysis along the predefined outer boundary of the solid element model.

The layered shell model included the IC structure from the top of its base-raft to its full height with the SG openings (Figure 1). Considering the symmetry, only half of the structure was modeled including IC dome, ring beam and wall; passive reinforcements and prestressing ducts were included as layers. Finite element meshing was done to conform to the actual locations of the prestressing forces. EPs were not included in the layered shell model. Two-dimensional composite planer shell elements were used to model the IC dome, wall and ring beam. 
Dome along with the ring beam was modeled using triangular elements ( 3 and 6 noded) while the wall was modeled using quadrilateral elements (4 and 8 noded) (Figure 2, Figure 3) with 5 relevant degrees of freedom at each node. Both the passive reinforcements and the prestressing ducts of the IC dome are in the vertical planes forming the orthogonal grids. Details of the layered shell element used to model the IC dome is shown in Figure 4. Four orthotropic layers (two at top and two at bottom) were considered to represent the four layers of reinforcements. Each of these layers was assigned all the relevant properties of concrete, except for a different modulus of elasticity value in the direction of placement of reinforcements computed based on transformed section with due regards for the variation of reinforcement details. The prestressing ducts in each orthogonal direction were considered as an isotropic layer of thickness equal to the diameter of the duct. The properties of each orthogonal layer were computed based on the variation of details of the ducts over the different regions of the IC dome.

Only the thickened region around the SG openings including the transition region, was considered in the solid element model (Figure 5). Prestressing ducts passing through the region modeled, were included in the solid element model in line with their actual details. Thus, the prestressing forces were applied as line loads in the corresponding ducts. Steel EPs and steel-concrete interface around the SG openings were modeled (Figure 6). Loop cable ducts and passive reinforcements were not included in the model; however, the forces of the loop cables were included. 4 and 10 noded isoparametric solid tetrahedron elements were used for modeling the thickened and transition regions of the IC dome. 4 and 8 noded two-dimensional planar shell elements having 5

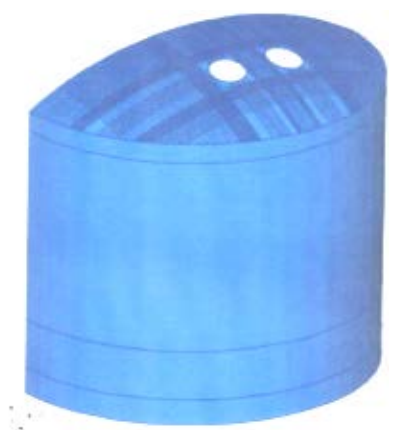

Figure 1. Isometric view of layered shell model.

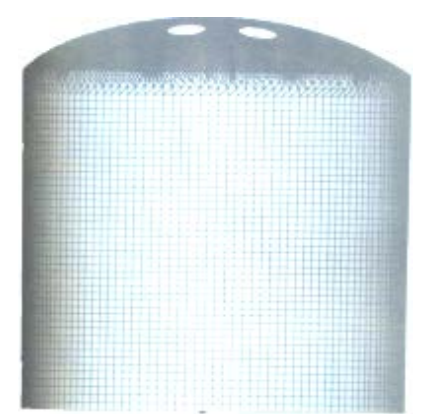

Figure 2. Front view of the layered shell model showing meshing details.

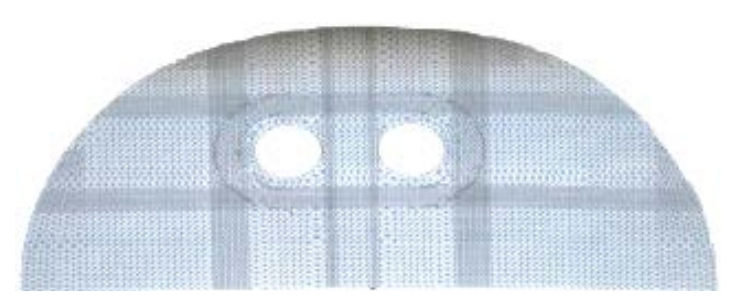

Figure 3. Plan view of the layered shell model showing meshing details. 


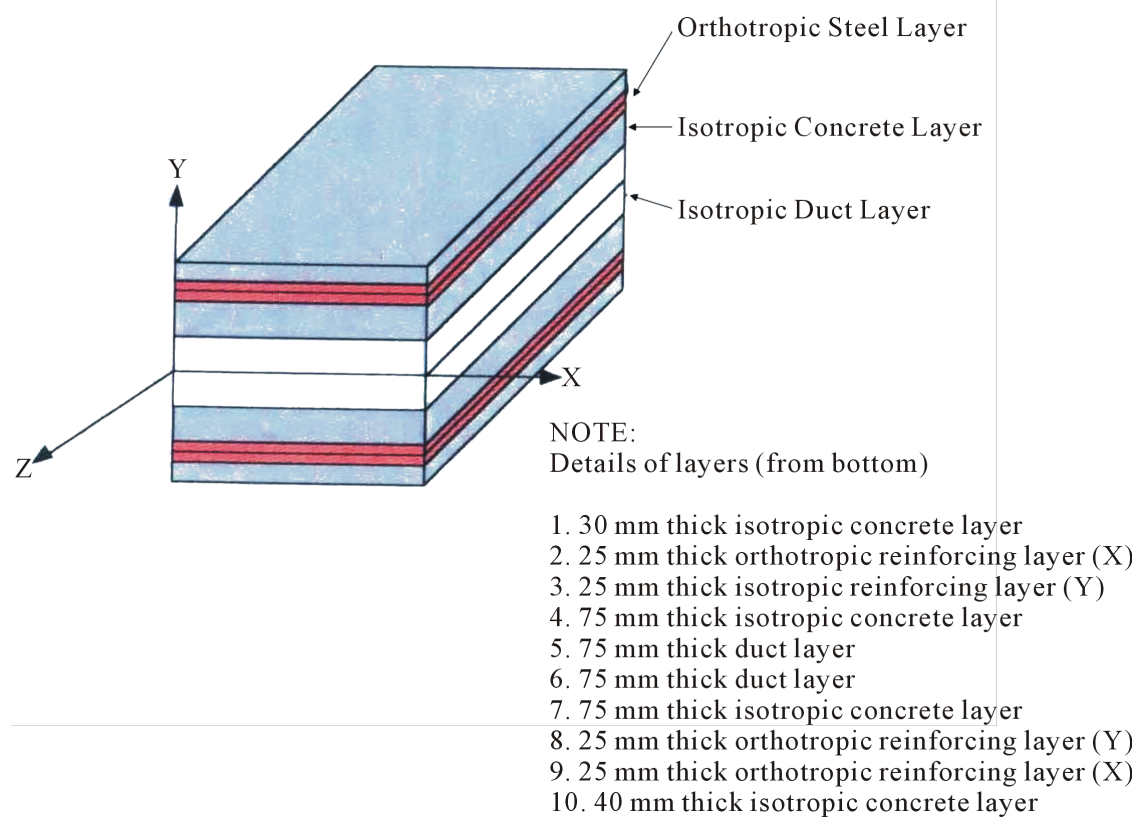

Figure 4. Details of layers in the layered shell element.

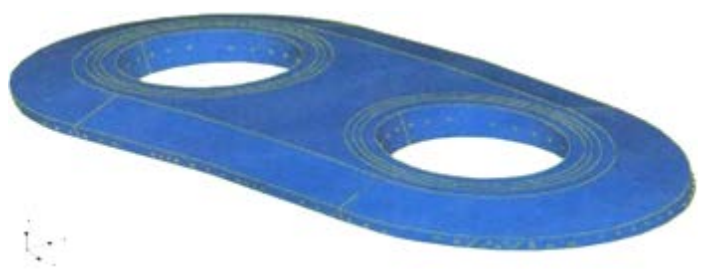

Figure 5. Solid element model with SG openings and prestressing ducts.

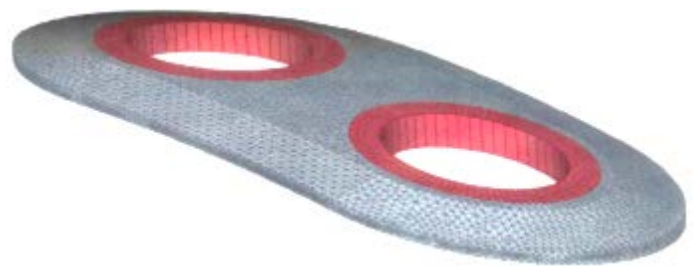

Figure 6. Isometric view of solid element model showing embedded steel plates around SG openings.

degrees of freedom at each node, was used for modeling steel EPs at SG openings. One-dimensional bar element was used to model the main anchors of the steel EPs. The interface zone between steel EPs and the dome concrete was modeled using one dimensional GAP element having connectivity with both the steel and concrete elements. The details about the GAP elements have been presented elsewhere [10].

Prestressing of IC wall and IC ring beam was considered in the layered shell model in terms of equivalent pressure and anchorage forces as derived from the actual prestressing details adopted. In the layered shell model, the dome prestressing forces were applied at their actual locations as line loads with due considerations for the cable profiles. Prestressing anchorage forces were applied in the form of nodal forces. Prestressing forces due to the loop cables were applied in the layered shell model as nodal forces at appropriate locations.

In the solid element model, the prestressing ducts passing through the thickened and transition regions around the SG openings were modeled according to their actual details. The corresponding prestressing forces for each duct were applied in line with their actual locations as line loads acting radially inwards in respective vertical 
planes; the anchorage forces at the periphery of the SG openings were applied as appropriate nodal forces. Although the loop cable ducts were not included in the solid element model, but the prestressing forces of the loop cables were applied.

Following material properties were adopted for the analysis:

- Concrete elements in the IC wall: characteristic strength = 35 MPa; Young's Modulus $=29580$ MPa; Poisson's ratio $=0.2$;

- Concrete elements in the IC dome and ring beam: characteristic strength $=60 \mathrm{MPa}$; Young's Modulus $=$ 38730 MPa; Poisson's ratio $=0.2$;

- Steel elements: Yield stress $=250 \mathrm{MPa}$; Young's Modulus $=200 \mathrm{GPa}$; Poisson's ratio $=0.3$.

In order to examine the convergence trend of the analysis, following two mesh-types were analysed for the two types of model:

Layered shell model:

- Mesh type 1: This mesh type has 14,500 elements, 8950 nodes with aspect ratio of elements in the range 1.2 - 3.0 (Figure 7);

- Mesh type 2: This mesh type has 10,500 elements, 6100 nodes with aspect ratio of elements in the range 1.8 - 3.3 (Figure 8).

Solid element model:

- Mesh type 1: This mesh type has 90,500 elements, 25,500 nodes with aspect ratio of elements in the range 1.5 - 3.0 (Figure 9);

- Mesh type 2: This mesh type has 66,000 elements, 16,500 nodes with aspect ratio of elements in the range 2 - 3.5 (Figure 10).

\section{Results and Discussion}

Two types of finite element models, layered shell model and solid element model, were analysed for initial prestress transfer condition. The layered shell analysis gave the overall behavior of the structure in terms of deformation and stress contours. The results [11] of the layered shell analysis indicated that the vertical displacements are the predominant displacements of the IC dome at prestress transfer. Accordingly, the vertical displacements as obtained from the layered shell analysis along the pre-selected boundary of the solid element model, were applied as the enforced displacements for the selected nodes of the boundary of the solid element model along with suitable constraints at some nodes (Figure 11). The results from the solid element analysis were of help for studying the local behavior of the structure at and around the SG openings in the IC dome; these results were

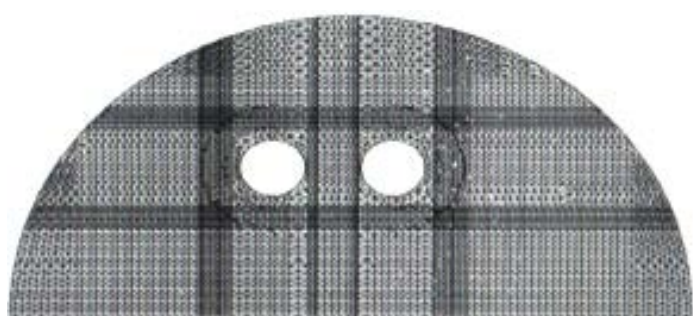

Figure 7. Plan view mesh type-1 for layered shell analysis.

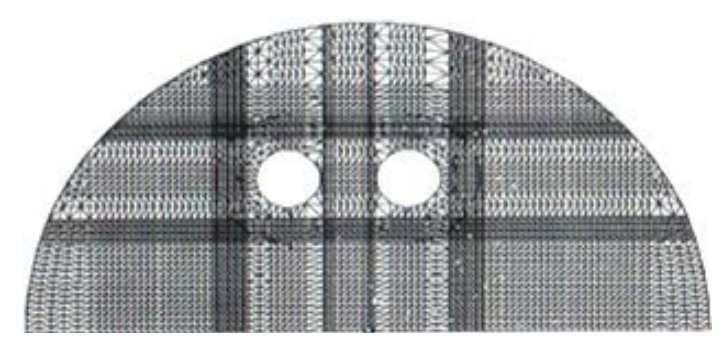

Figure 8. Plan view of mesh type-2 for layered shell analysis. 


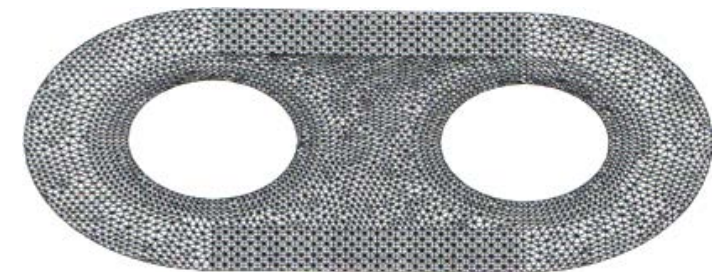

Figure 9. Plan view of mesh type-1 for solid element model.

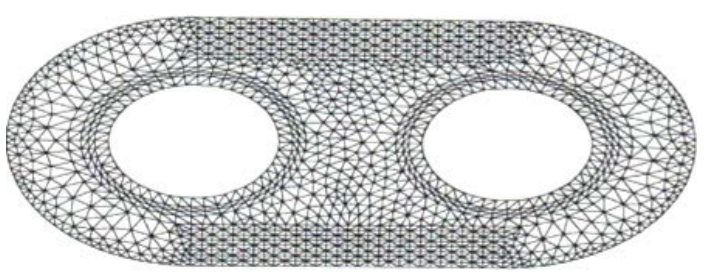

Figure 10. Plan view of mesh type-2 for solid element model.

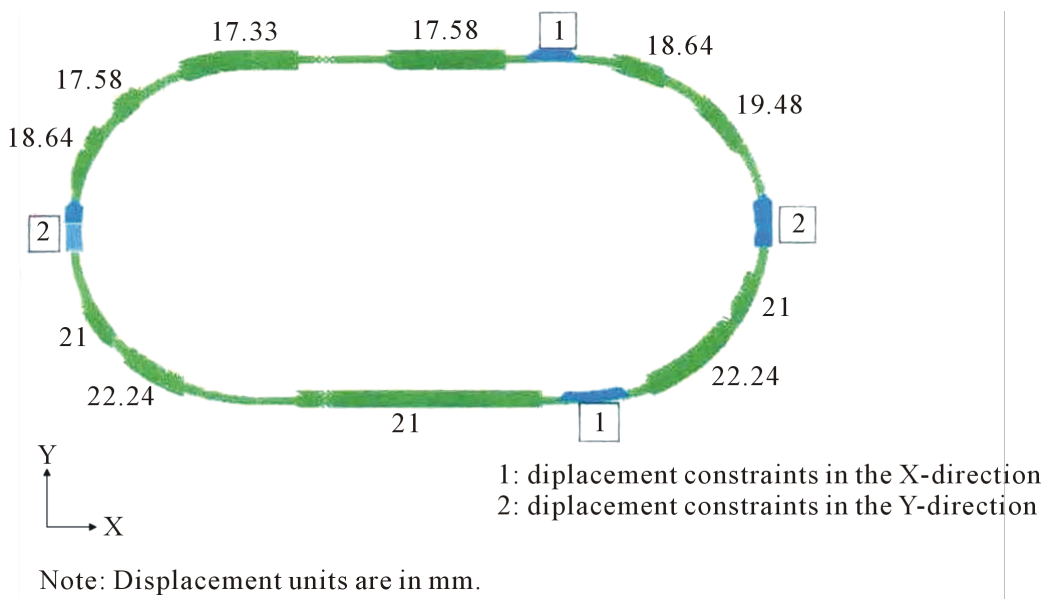

Figure 11. Boundary conditions for solid element model.

obtained as deformation contours, stress contours, axial displacement data, lateral displacement data and slip data at the steel plate-concrete interface as represented by the GAP elements.

\subsection{Results from Layered Shell Analysis}

The results of the layered shell analysis have been presented in the forms of deformation data and stress data (major principal stress, minor principal stress and von-Mises stress) for the purpose of illustrating the overall behavior of the structure.

\subsubsection{Deformation}

Following have been observed from the scrutiny of the displacement contours (Figures 12-16):

- Vertical displacements (Z-direction) are the predominant displacements in the dome portion.

- The maximum vertical displacement of $24.35 \mathrm{~mm}$ has been observed to occur around the locations where prestressing ducts are closely spaced.

- The ring beam has been found to be displaced predominantly in vertically downward direction by about 11.2 $\mathrm{mm}$ and showed very small $(1.1 \mathrm{~mm})$ radially inward horizontal displacement.

- The wall has been found to be displaced in inward direction with the maximum displacement of $10.1 \mathrm{~mm}$ occurring at about $33.1 \mathrm{~m}$ to $37.5 \mathrm{~m}$ above the base of the IC structure. 


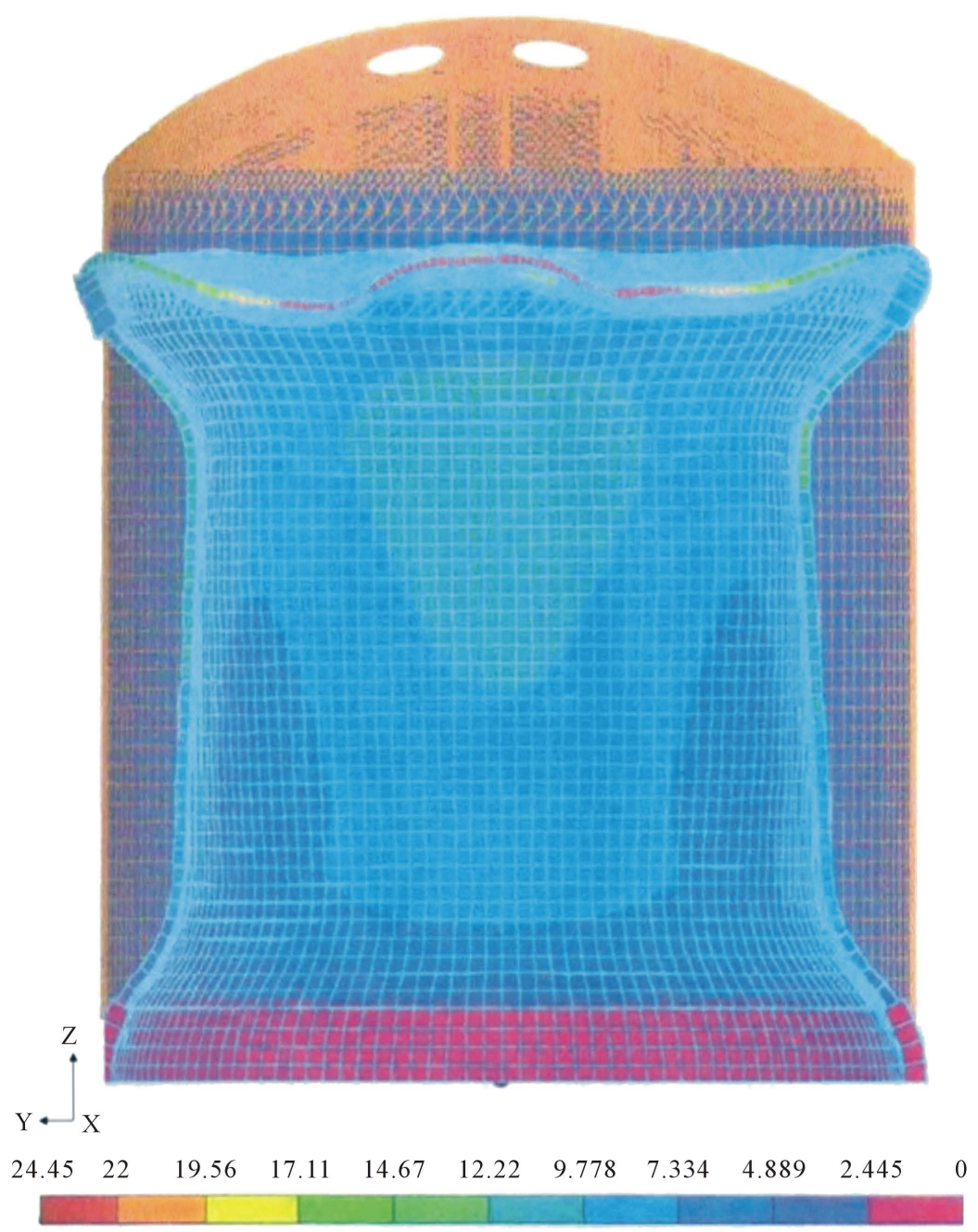

Note: Units are in $\mathrm{mm}$

Figure 12. Total displacement contour with deformed shape for the layered shell model in elevation.

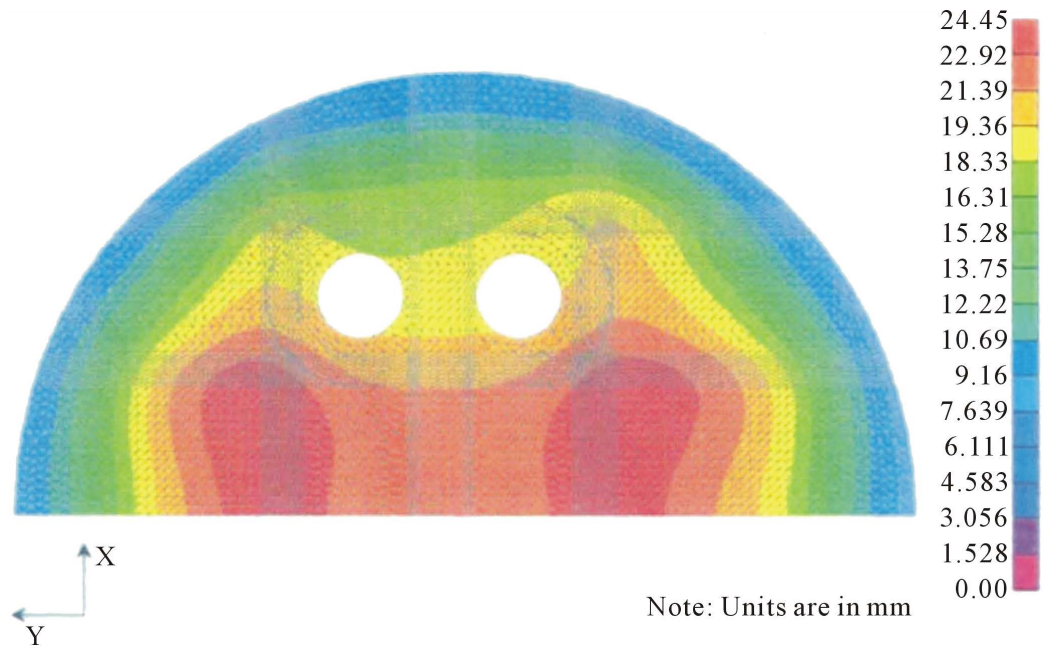

Figure 13. Total translation contour for the layered shell model in plan. 


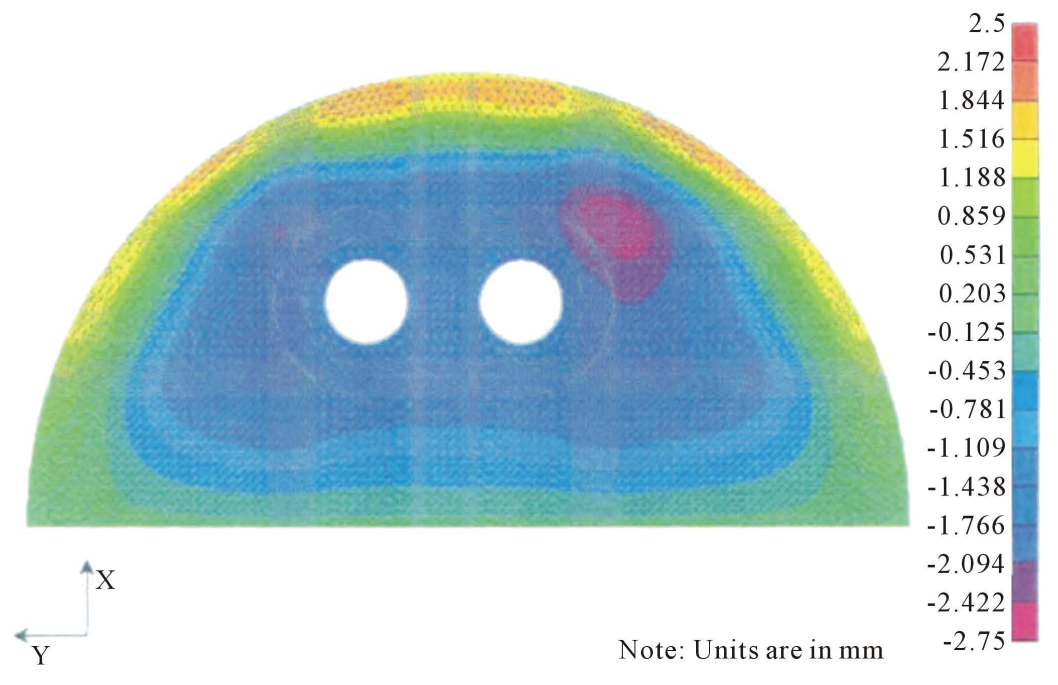

Figure 14. X-translation contour for the layered shell model in plan.

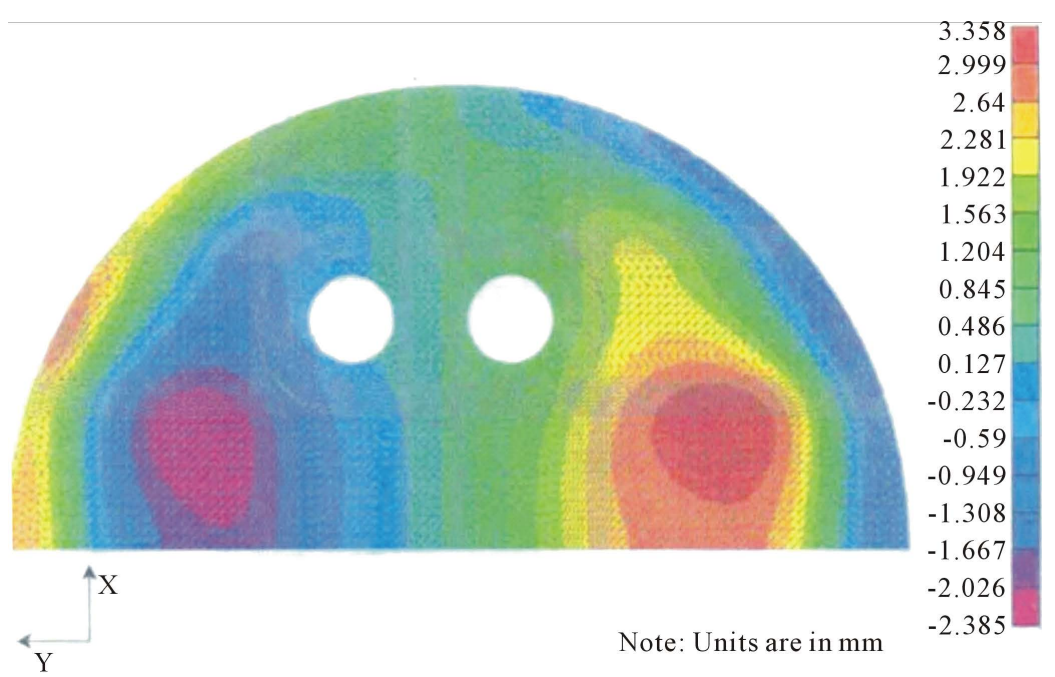

Figure 15. Y-translation contour for the layered shell model in plan.

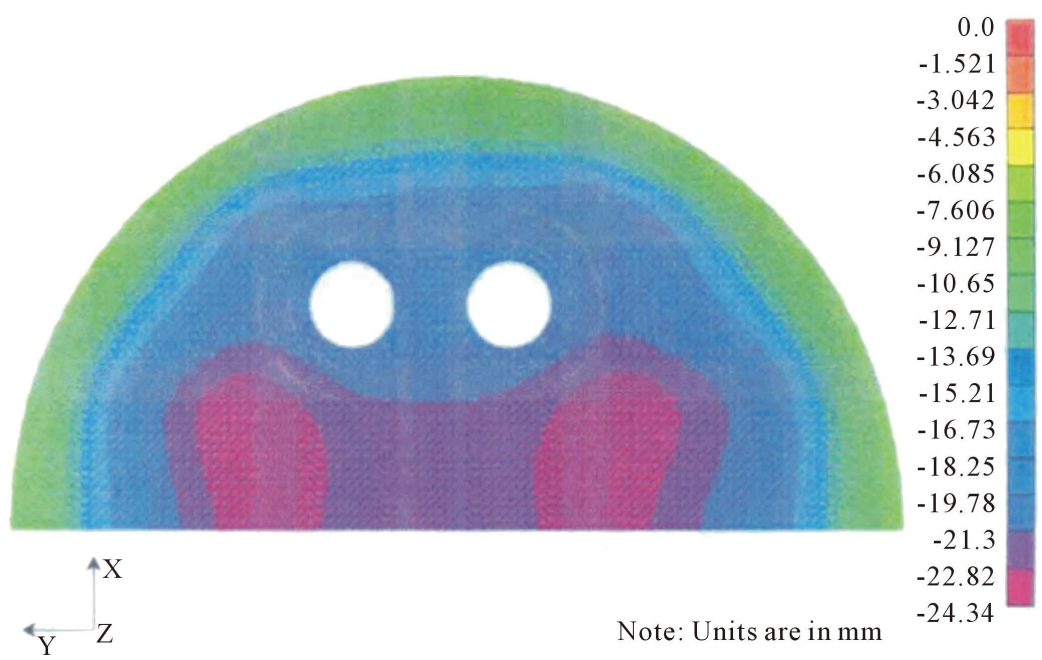

Figure 16. Z-translation contour for the layered shell model in plan. 
- The deformation pattern of the dome is not axisymmetric; however, the same of the wall has been found to be predominantly axisymmeric.

\subsubsection{Stresses}

1) Major Principal Stresses

a) Major Principal Stresses in Dome Portion (Figure 17)

The entire dome portion has been found to be subjected to the magnitude of the major principal stress ranging between 11.0 MPa (compressive) and 2.25 MPa (tensile). But, at some of the locations of the dome near the ring beam, high tensile stresses of magnitude 6.0 MPa have been observed possibly due to prestressing anchorage forces. The entire thickened and transition region has been found to have a major principal stress of $7.15 \mathrm{Mpa}$ (compressive) to $0.4 \mathrm{Mpa}$ (tensile).

b) Major Principal Stresses in the Ring Beam and Wall (Figure 18)

In the IC wall the magnitudes of the major principal stress have been found to be about $8.4 \mathrm{MPa}$ (compressive) - 11.1 MPa (compressive), predominantly, excepting for the regions located just below the ring beam and just above the thickened portion of the IC wall, wherein, the same have been observed to be about 4.0 MPa (compressive) - 5.3 MPa (compressive). The maximum principal stress of magnitude $13.5 \mathrm{MPa}$ (compressive) has been found at elevations of $8.3 \mathrm{~m}$ and $39.1 \mathrm{~m}$ above the base of wall. In the thickened portion of IC wall (i.e., at the base), the major principal stress has been observed to be in the range of $0.3 \mathrm{MPa}$ (compressive) - 2.8 MPa (compressive).

In the ring beam, the magnitudes of major principal stress have been found to be about $1.6 \mathrm{MPa}$ (tensile) - 2.2 MPa (compressive), excepting for a magnitude of 6.0 MPa (tensile) at some discrete locations possibly due to the prestressing anchorage forces applied at these locations.

\section{2) Minor Principal Stresses}

a) Minor Principal Stresses in Dome Portion (Figure 19)

The entire dome has been found to have the magnitudes of the minor principal stresses in the range of 4.7 MPa (compressive) - 16.2 MPa (compressive). At springing level, where the dome rests on the ring beam, the magnitudes of the minor principal stresses have been observed to be about $20 \mathrm{MPa}$ (compressive) - 29.5 MPa (compressive). Higher magnitudes of minor principal stresses, of about 27.6 MPa (compressive) - 29.5 MPa (compressive) have been found to develop at the locations where the prestressing ducts are closely spaced at the springing level. The entire thickened (along with the transition region) has been found to have minor principal stresses of about 4.7 MPa (compressive) - 12.3 MPa (compressive).

b) Minor Principal Stresses in Ring Beam and Wall (Figure 20)

In the IC wall, the magnitudes of the minor principal stress have been found to be about $8.3 \mathrm{MPa}$ (compressive) - 15.2 MPa (compressive) predominantly in the entire wall, excepting in the thickened portion of the wall (at the base), wherein the same have been observed to be about 1.5 MPa (compressive) - 4.9 MPa (compressive). In the ring beam, these values have been found occurring in the range of $1.5 \mathrm{MPa}$ (compressive) - $8.3 \mathrm{MPa}$ (compressive).

\section{3) Von-Mises Stresses}

a) Von-Mises Stresses in Dome (Figure 21)

In the dome, the von Mises stresses have been observed to be in the range of 5.0 MPa - 14.2 MPa; but, higher magnitudes of the von Mises stresses of about 26.4 MPa - 29.4 MPa have been found to occur in the locations near the ring beam when the prestressing cables are closely spaced. In the thickened region (including the transition region) of the dome, the von-Mises stresses of magnitudes 5.0 MPa - 9.6 MPa have been occurred.

b) Von-Mises Stresses in the Ring Beam and Wall (Figure 22)

The magnitudes of von-Mises stresses have been observed to be in the range of 1.4 MPa - 20.4 MPa in the wall, excepting for the lower magnitudes of about 1.4 MPa - 4.9 MPa occurring in the bottom thickened portion. In the ring beam, at anchorage locations of dome prestressing cables, the von-Mises stresses have been found to be in the range of 7.8 MPa - 11.6 MPa.

\subsection{Results from Solid Element Analysis}

The results obtained from the solid element analysis have been presented in the forms of deformation data, stress data (major principal stresses, minor principal stresses and von-Mises stresses); and axial force data, shear force 

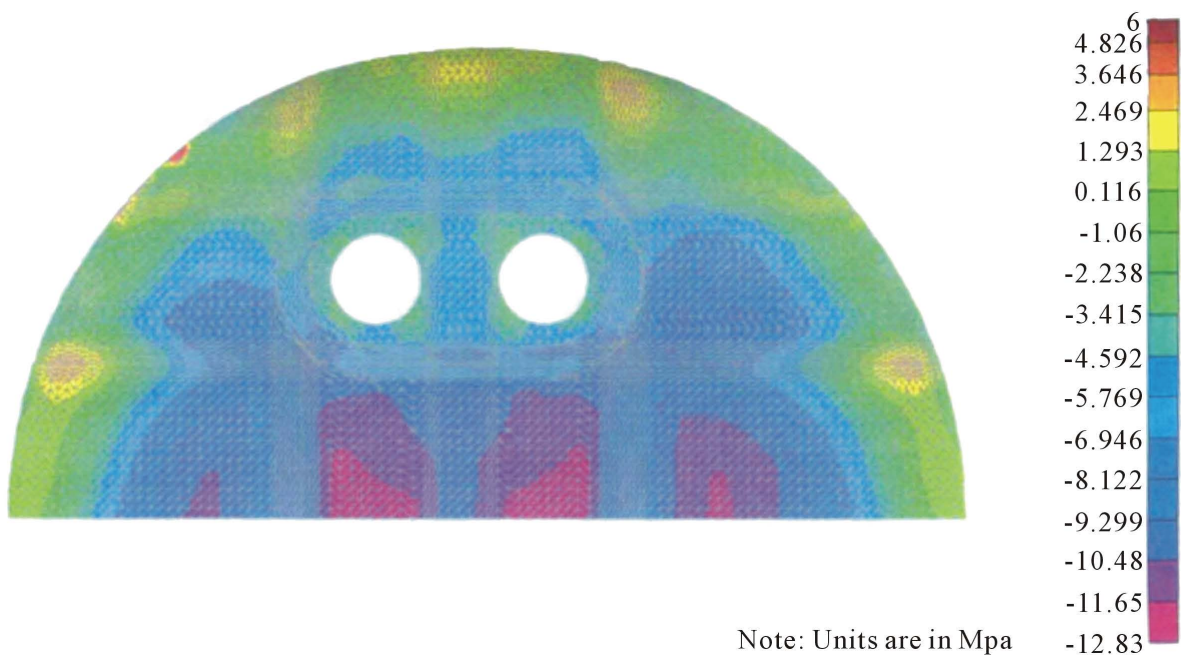

Figure 17. Major principal stress contour for dome.
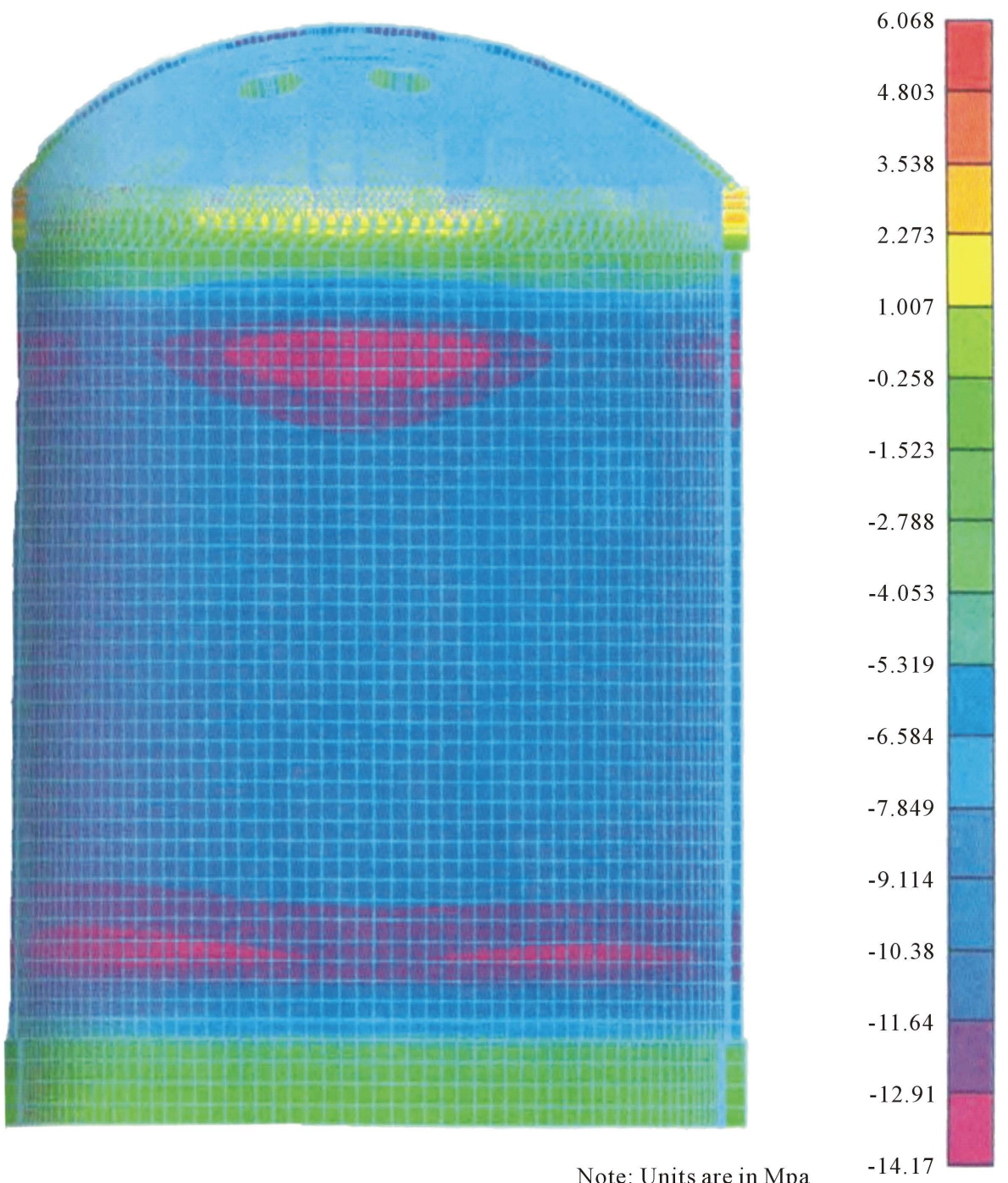

Figure 18. Major principal stress in IC wall and ring beam. 


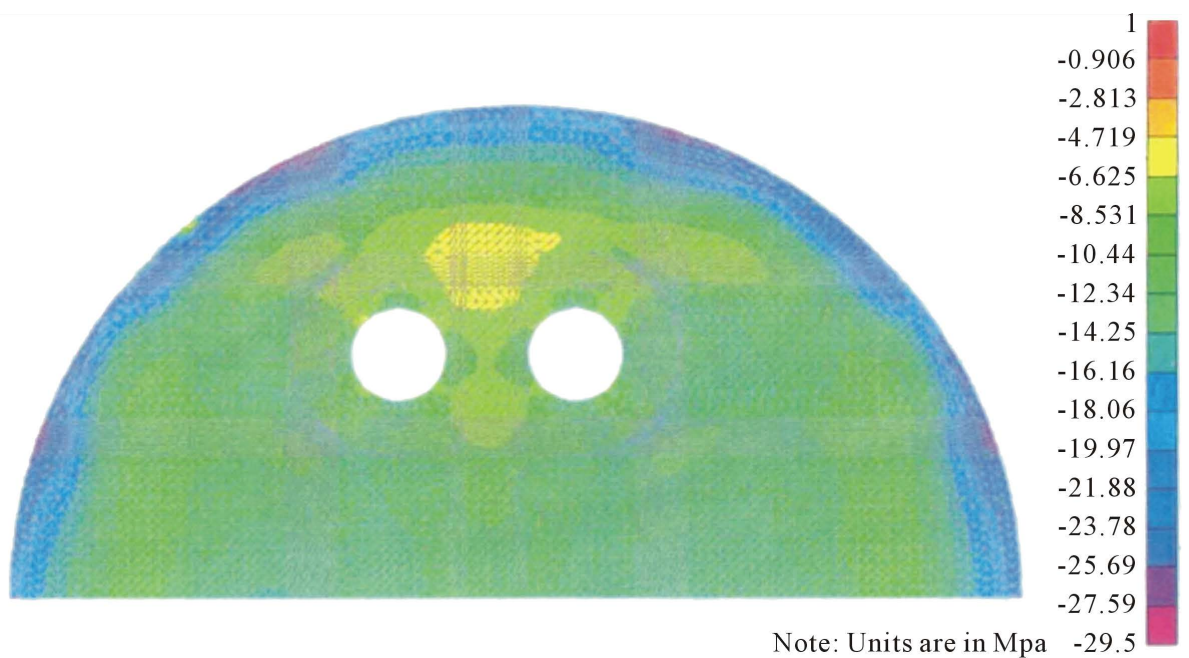

Figure 19. Minor principal stresses in IC wall and ring beam.
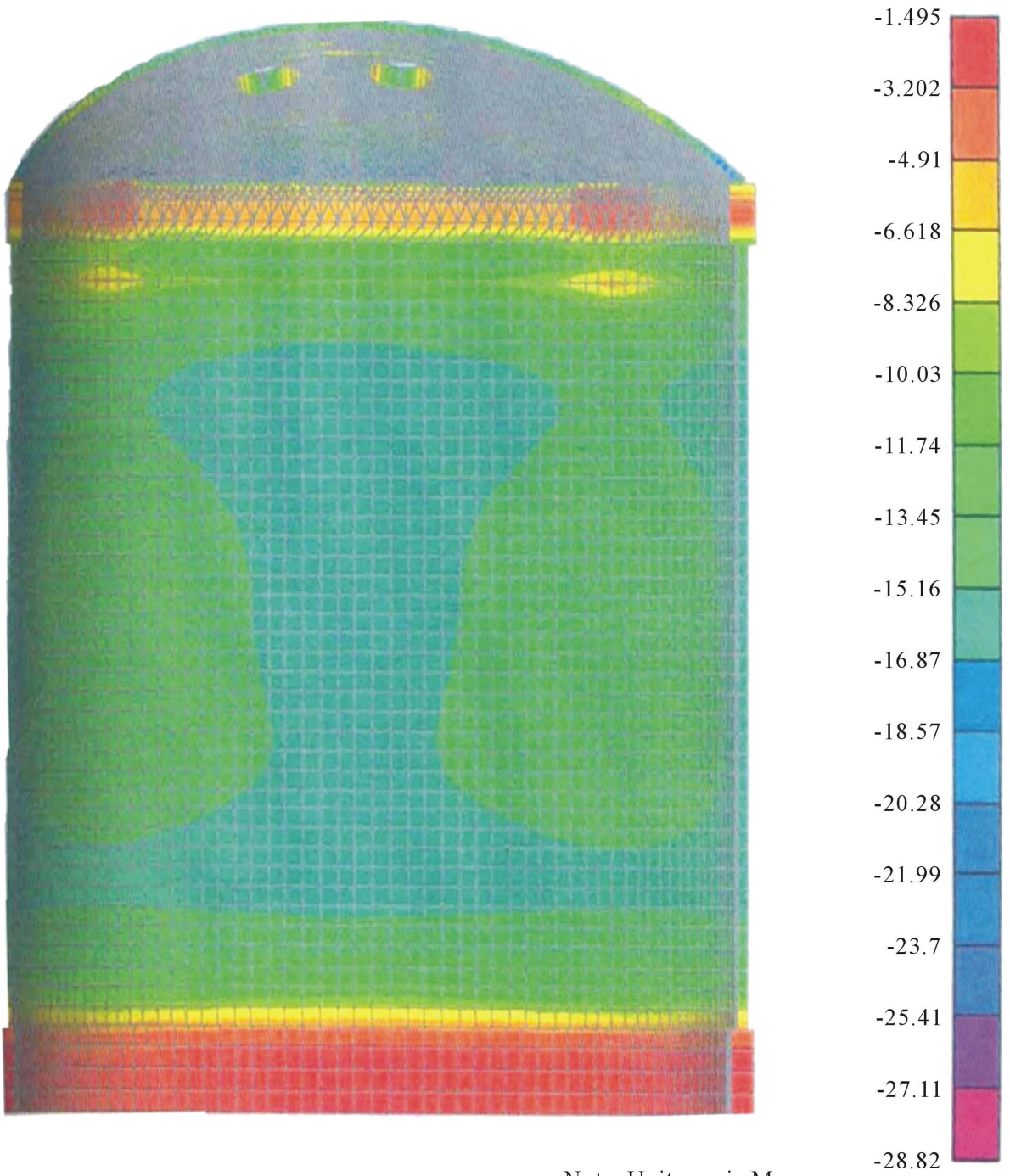

Note: Units are in Mpa

Figure 20. Minor principal stresses in IC wall and ring beam. 


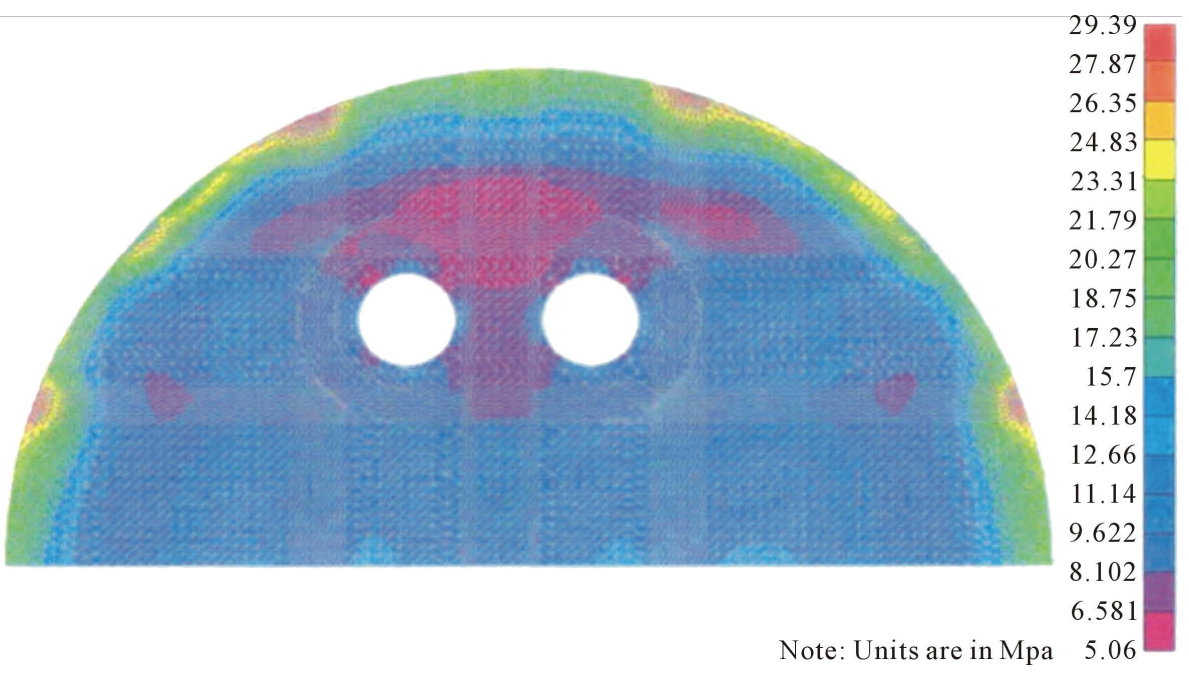

Figure 21. Von-Mises stresses in dome.
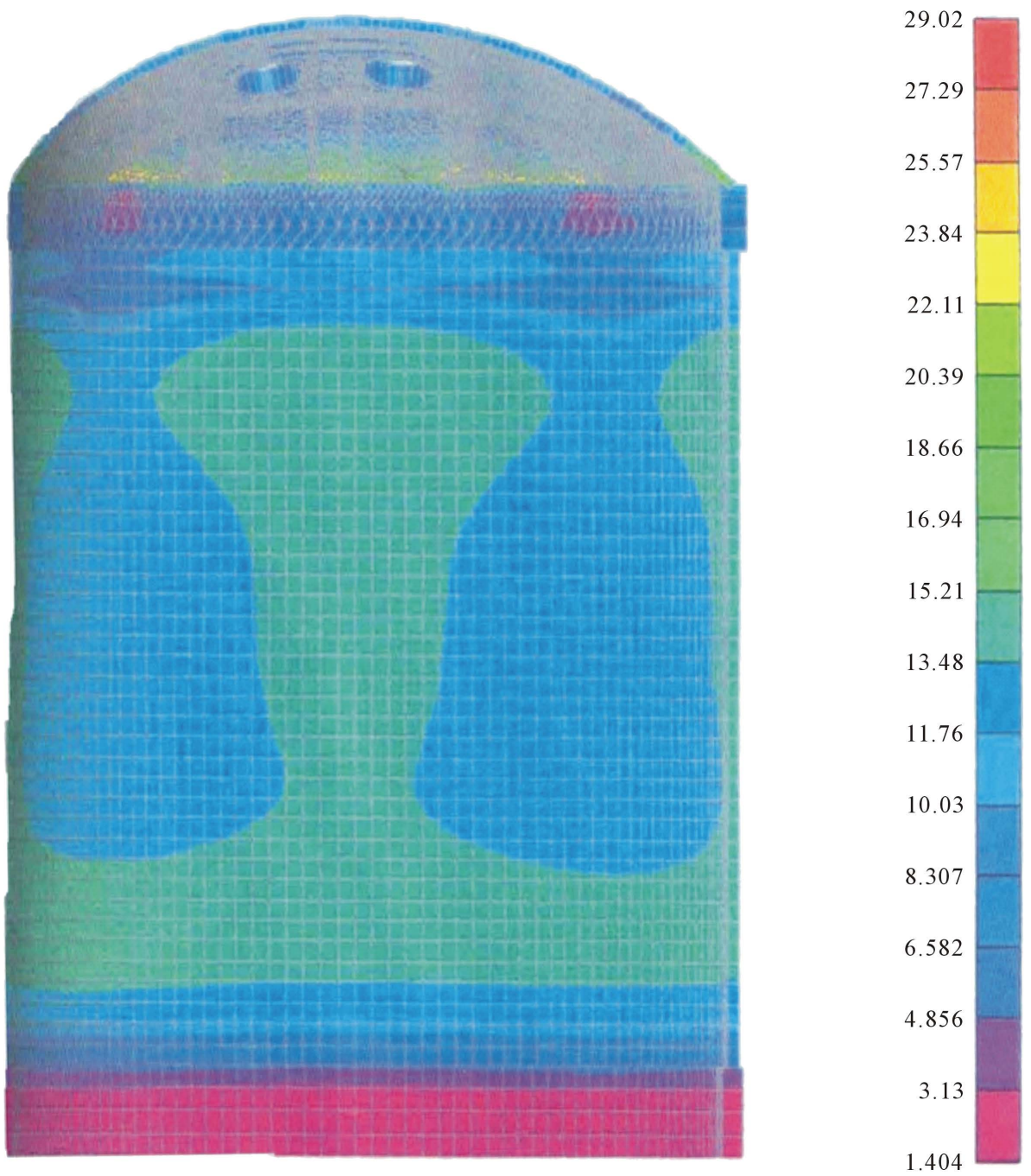

Note: Units are in Mpa

Figure 22. Von-Mises stresses in IC wall and ring beam. 
data, axial displacement data, lateral displacement data and slip data at the interface as represented by the gap elements. As illustrated in Figure 23, vertical planes $\mathrm{q}=\theta^{0}$ and $\mathrm{p}=\theta^{0}$ with their axes of revolution being the vertical axes of the SG openings SG1 and SG2 respectively, have been used for describing the results of the interface regions at SG openings.

\subsubsection{Deformation}

As illustrated in Figure 24, the pattern of the dominant vertical (downward) displacement in the thickened region (including the transition region) is of a symmetric one having trend of decreasing displacements towards the ring beam. The maximum vertical displacement of magnitude $22.24 \mathrm{~mm}$ has been found to occur at the junction where the transition region starts from the basic dome, occurring in the regions of $q=150^{\circ}-170^{\circ}$ and $\mathrm{p}=$ $190^{\circ}-210^{\circ}$ at SG1 and SG2 respectively. The minimum vertical displacement of magnitude $17.33 \mathrm{~mm}$ has also been observed at the junction of the transition region with the basic dome; but, on the side of the ring beam. The entire thickened portion surrounding SG1 and SG2 has been found to have undergone the vertical displacements of magnitudes in the range of $18.4 \mathrm{~mm}-20.2 \mathrm{~mm}$.

\subsubsection{Stresses}

\section{1) Major Principal Stresses (Figure 25)}

Almost the entire thickened portion (along with the transition region) surrounding the SG openings, has been found to have the major principal stresses of about 0.625 MPa (compressive) - 2.5 MPa (compressive) excepting for some regions of tensile major principal stresses of magnitude $0.625 \mathrm{MPa}$ occurring in between the two SG openings.

2) Minor Principal Stresses (Figure 26)

Almost the entire thickened portion(along with the transition region)surrounding the SG openings, has been observed to have the minor principal stresses in the range $1 \mathrm{MPa}$ (compressive) - $17 \mathrm{MPa}$ (compressive) excepting for some specific locations near the edges of SG openings, where tensile minor principal stress of about

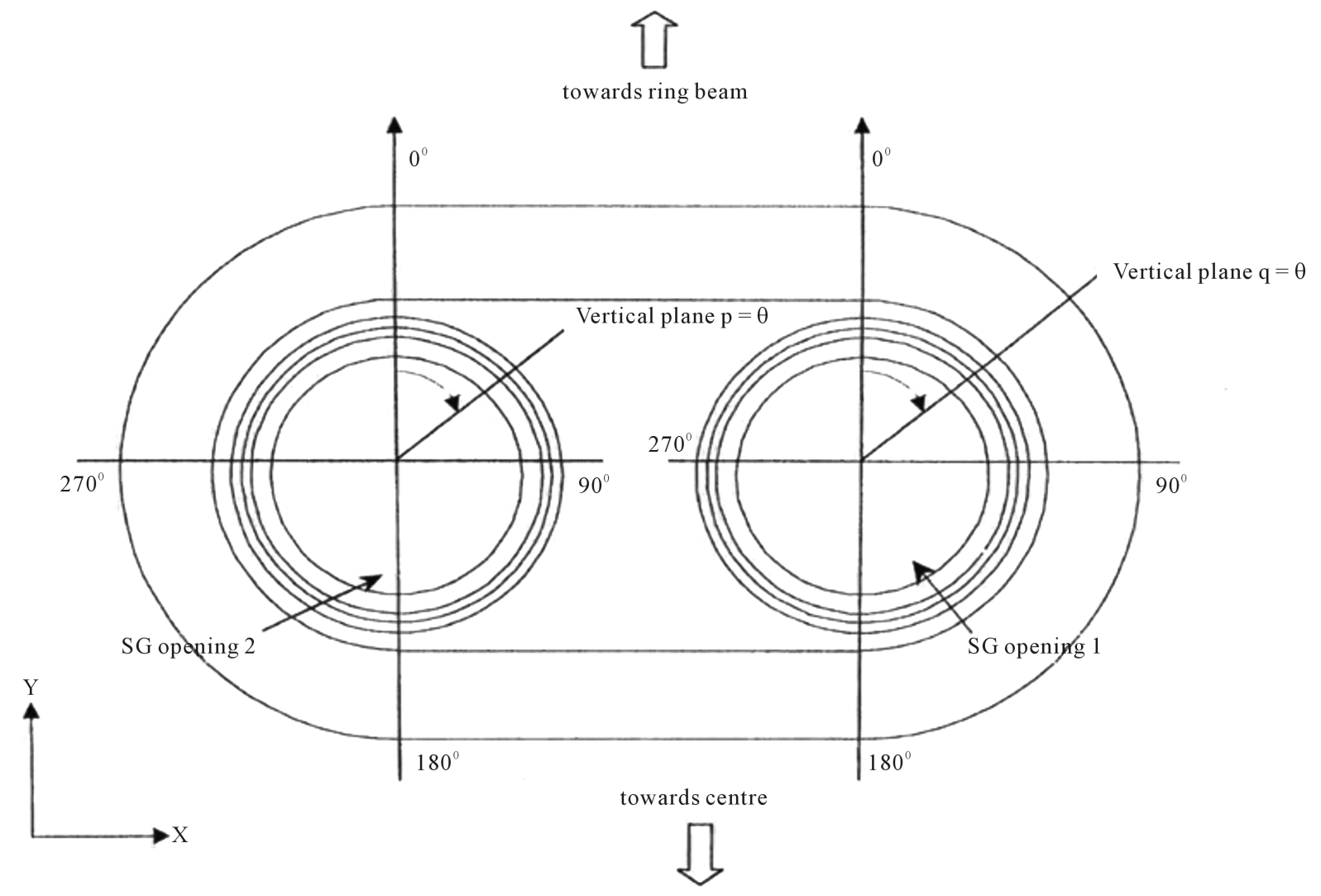

Figure 23. Key plan showing vertical planes through SG openings. 


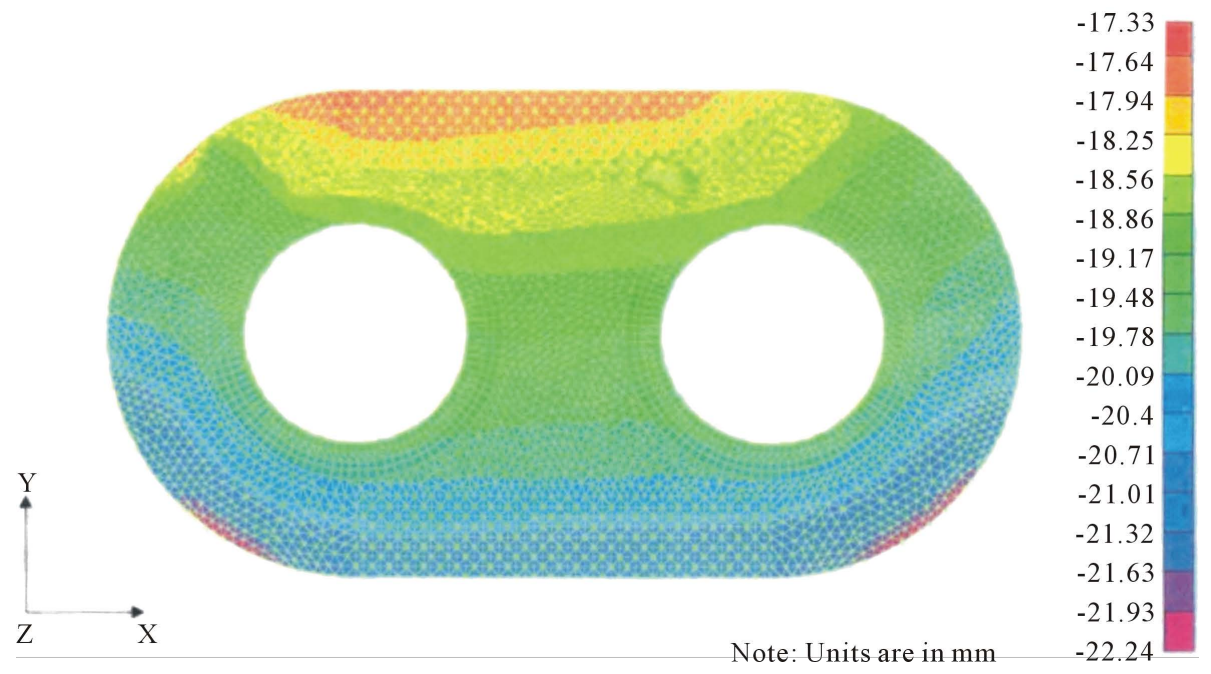

Figure 24. Vertical (z-direction) displacement contour for solid element model.

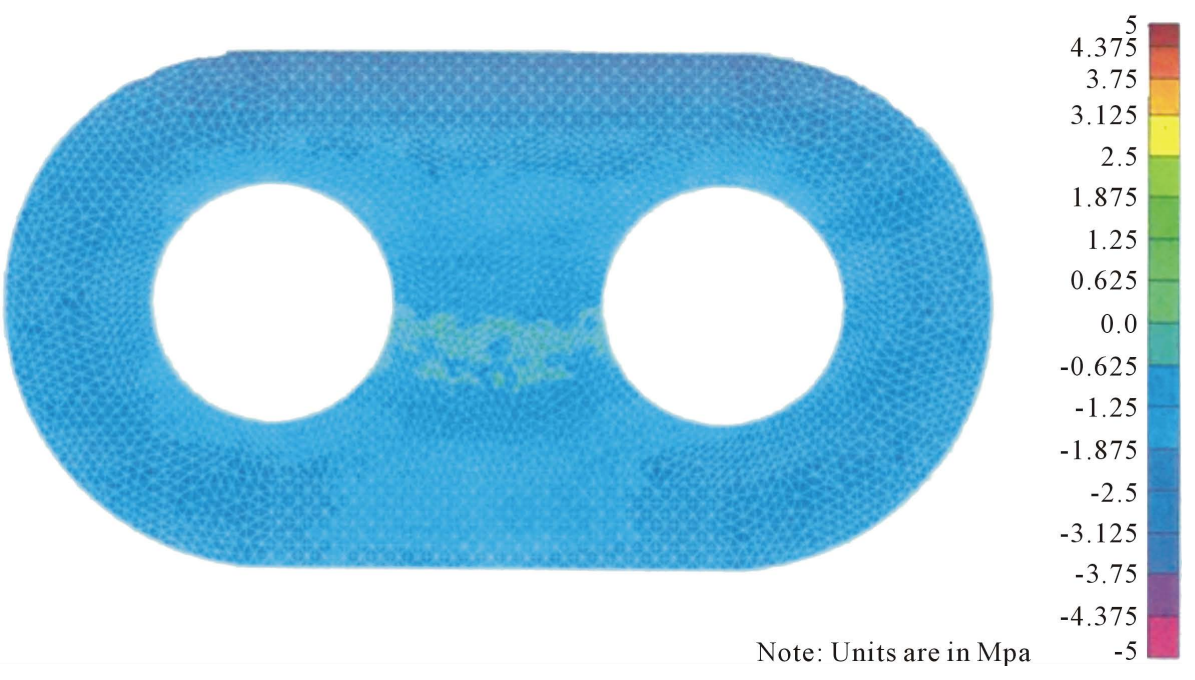

Figure 25. Major Principal stress contour for solid element model.

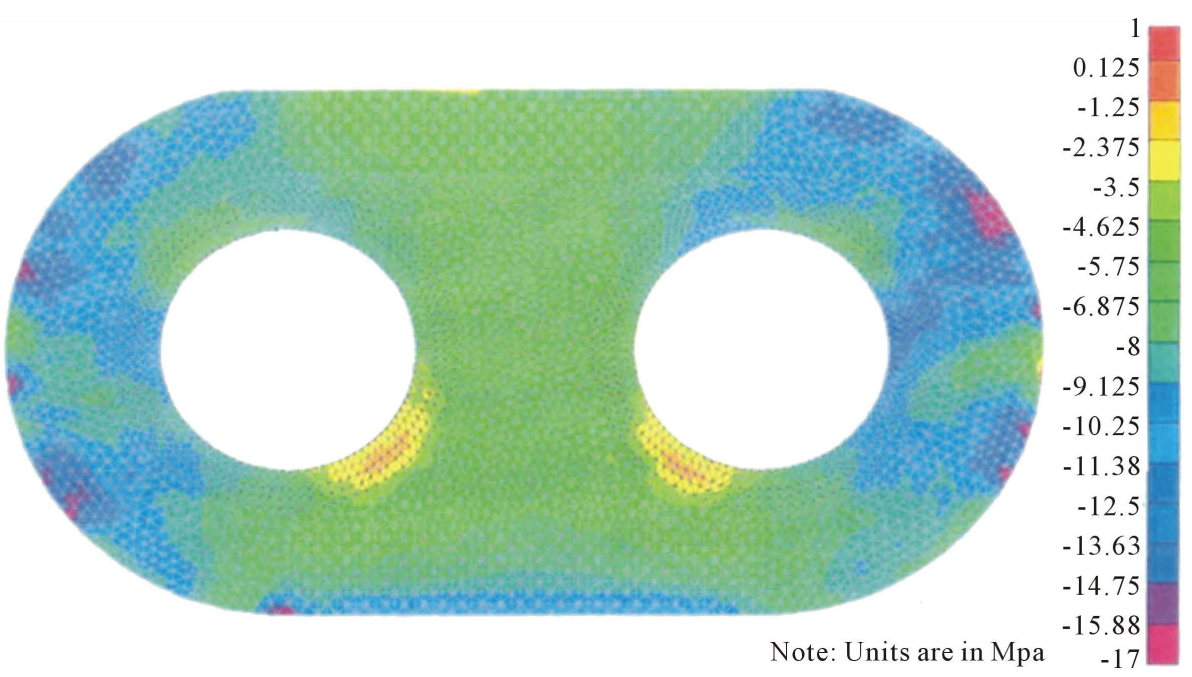

Figure 26. Minor principal stress contour for solid element model. 
$0.125 \mathrm{MPa}$ has been developed.

3) Von-Mises Stresses (Figure 27)

The entire thickened portion (along with the transition region) surrounding the SG openings, has been found to develop the von-Mises stresses in the range, 5.5 MPa - 7.5 MPa with relatively higher values occurring in the transition zone as compared to the thickened region.

\subsubsection{Results of the Interface Regions at SG Opening}

The force data of the GAP elements used for modeling the interface zone between EPs and the dome concrete has been converted into stresses using the corresponding tributary areas. Following important observations have been made based on the analysis output data [11] on axial stresses, shear stresses, axial displacements and slips of the GAP elements:

- Open gap status has been observed in the GAP elements lying mainly in the interface zone at the top surface embedded plate in the region $\mathrm{q}=155^{\circ}$ to $265^{\circ}$ for SG1 and $\mathrm{p}=95^{\circ}$ to $210^{\circ}$ for SG2 (Figure 23). Closed but sliding status has been observed for the GAP elements lying mainly in the interface zone at the vertical cylindrical embedded plate in the region $\mathrm{q}=155^{\circ}$ to $265^{\circ}$ for SG1 and $\mathrm{p}=95^{\circ}$ to $210^{\circ}$ for SG2 (Figure 23).

- Magnitudes of the axial displacements of the GAP elements of the influence zone at the top surface embedded plate have been found to be in the range of $0.004 \mathrm{~mm}$ (elongation) - $0.002 \mathrm{~mm}$ (compression) excepting in the region of $\mathrm{q}=155^{\circ}$ to $265^{\circ}$ for SG1 and $\mathrm{p}=95^{\circ}$ to $210^{\circ}$ for SG2 (Figure 23), where the axial displacements of the GAP elements have been observed to be as high as $0.015 \mathrm{~mm}$. The GAP elements of the interface zone adjacent to the vertical cylindrical embedded plate have been found to be undergoing relatively very small amount of axial deformation with most of them have been observed to be in compression.

- The entire interface zone adjacent to the top surface embedded plate has been found to have normal stresses in the range of 0.5 MPA (tensile) - 2.5 MPa (compressive) with relatively high values of tensile stresses of about 1.0 MPa - 1.5 MPa occurring in the region, $q=155^{\circ}$ to $265^{\circ}$ for SG1 and $p=95^{\circ}$ to $210^{\circ}$ for SG2. The interface zone adjacent to the vertical cylindrical embedded plate has been found to be under compression with an observed range off normal stresses of about $0.1 \mathrm{MPa}-1.8 \mathrm{MPa}$.

- Large number of GAP elements lying in the interface zone adjacent to the vertical cylindrical embedded plate have been found to be under closed status (but sliding) with the magnitudes of the respective resultant displacement of about $0.01 \mathrm{~mm}-0.068 \mathrm{~mm}$; relatively higher magnitudes of sliding displacements have been observed to be occurring in the regions, $q=155^{\circ}$ to $265^{\circ}$ for SG1 and $\mathrm{p}=95^{\circ}$ to $210^{\circ}$ for SG2. Relatively, the slip-displacements of the GAP elements of the interface zone adjacent to the top surface plate have been found to be of much less magnitudes.

- Shear stresses of magnitudes, ranging between 0.01 MPa and 0.188 MPa, have been observed in the GAP elements present in the interface zone adjacent to the vertical cylindrical embedded plate with the corresponding GAP elements having closed and sliding status. Relatively, much lower values of shear stresses

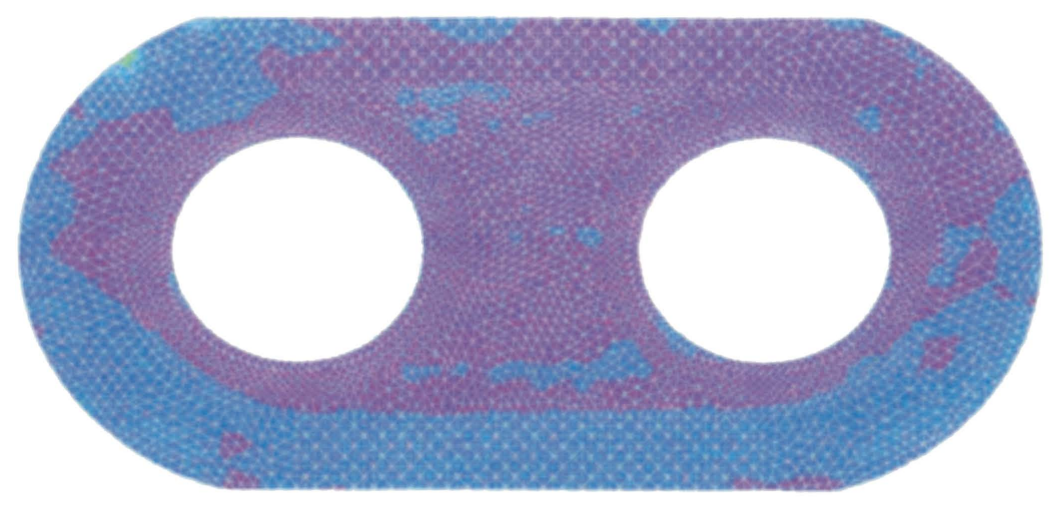

Note: Units are in Mpa

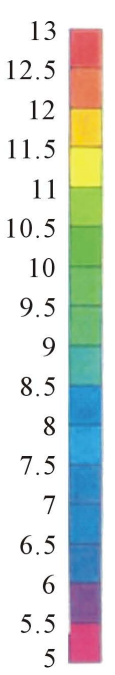

Figure 27. Von-Mises stress contour for solid element model. 
have been observed in the GAP elements of the interface zone adjacent to the top surface embedded plate.

- From above, it is evident that the regions bounded by $q=155^{\circ}$ to $265^{\circ}$ for SG1 and $\mathrm{p}=95^{\circ}$ to $210^{\circ}$ for SG2, can be regarded as the critical regions for possible separation between steel plate and adjacent concrete. The GAP elements representing the interface zone adjacent to the top surface embedded plate in the above regions show the open gap status with relatively higher values of axial displacements, while the GAP elements adjacent to the vertical cylindrical embedded plate lying in the same regions, show closed but sliding status. Even though the tensile stresses in the same regions have been found to be low; but, considering possible low values of the tensile strength of the steel-concrete interface, these regions can be considered as the critical regions from the view point of possible leakage (Figure 28).

\subsection{Comparison with the Results of Past Studies}

The results obtained from the present analytical study have been compared [11] with those of the past two FE analytical studies [9] [10]. The pertinent features of the two past analytical studies and the novelty of the present study in relation to the past two studies, all being on the same PSC IC dome for its condition under initial prestress transfer, have been presented in section 1 of this paper. Following are the relevant comparisons:

\subsubsection{Comparison of the Results for Deformation}

Results of all the three studies indicate that the IC dome deflection is predominantly vertically downward due to initial prestress transfer with the following specific observations on the magnitude of maximum vertical displacement, location of the occurrence of maximum vertical displacement and the pattern of the deformation of the IC dome for the respective three studies:

Murali Mohan et al. [9] have predicted a maximum vertical displacement of about $29 \mathrm{~mm}$ occurring near the crown portion of the dome with the dome-deformation being predominantly axisymmetric in the region near the ring beam; however, the authors predicted that the central portion of the dome including and around the SG openings, deforms unsymmetrically possibly due to unsymmetric prestressing forces in the dome along with the relative locations of the SG openings.

Gandhi et al. [10] have predicted a maximum vertical displacement of about $28 \mathrm{~mm}$ occurring at a distance of about $7.8 \mathrm{~m}$ on both sides of the central plane of the reactor building where the prestressing cables are closely spaced with the similar deformation pattern of the dome as that of the observation made by Murali Mohan et al. [9] however, the authors predicted that the ring beam deforms predominantly in vertical downward direction by about $16 \mathrm{~mm}$ with the occurrence of very small $(0.85 \mathrm{~mm})$ radially inward displacement.

In the present study, based on the results of the layered shell analysis, the maximum vertical displacement of about $24 \mathrm{~mm}$ has been observed to occur around the locations where prestressing ducts are closely spaced with similar deformation pattern of the dome as those of the past two studies; however, the ring beam has been found

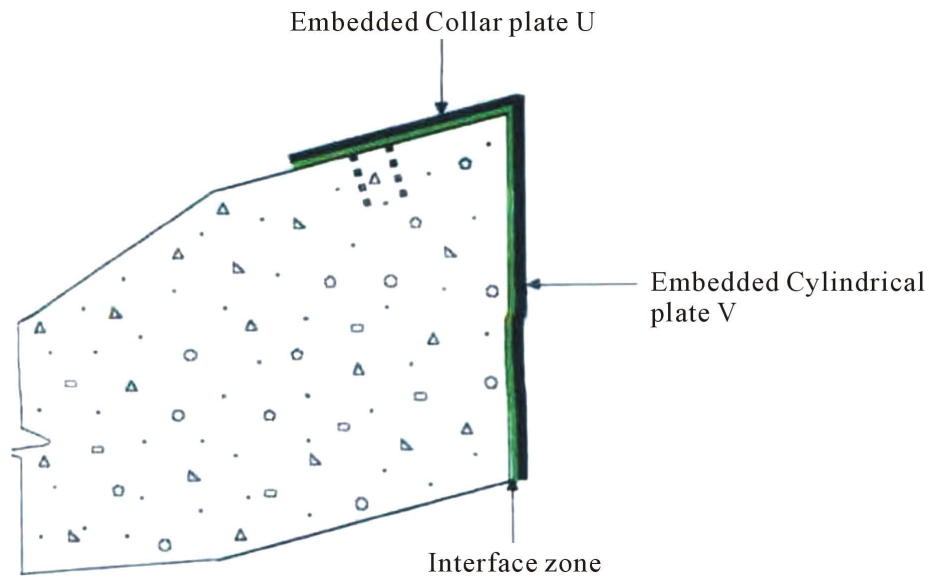

(a)

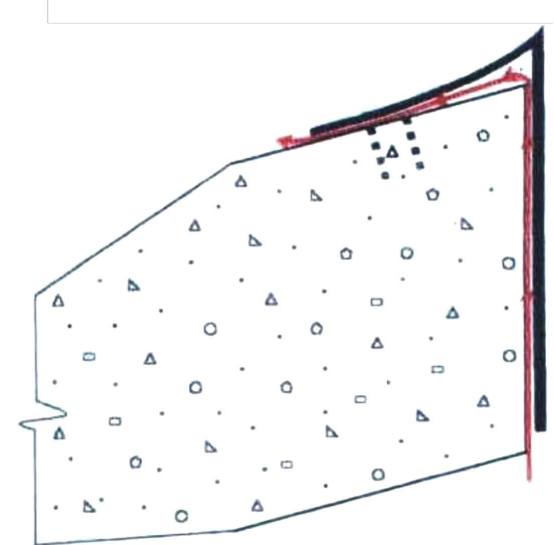

(b)

Figure 28. Details of possible leakage path in the regions $q=155^{\circ}$ to $265^{0}$ for SG1 and $p=95^{0}$ to $210^{\circ}$ for SG2. (a) Interface zone details; (b) Possible leakage path. 
to be displaced predominantly in vertically downward direction by about $11 \mathrm{~mm}$ with the occurrence of very small $(1.1 \mathrm{~mm})$ radially inward displacement.

The results of the solid element analysis of the present study provide some additional observations on the dome deformation pertaining to the thickened region of the dome around the SG openings including the transition region. Similar to the observations made in the past two studies and the layered shell analysis part of the present study, the pattern of the dominant vertical displacement in the thickened region (including the transition region) has been found to be asymmetric having trend of decreasing displacements towards the ring beam. The solid element analysis of the present study also predicted the maximum vertical displacement of about $22 \mathrm{~mm}$ occurring at the junction where the transition region starts from the basic dome and bounded by the regions of $\mathrm{q}$ $=150^{\circ}-170^{\circ}$ and $\mathrm{p}=190^{\circ}-210^{\circ}$ at SG1 and SG2 respectively. From the results of the solid element analysis, the minimum vertical displacement of $17.33 \mathrm{~mm}$ has been observed at the junction of the transition region with the basic dome occurring on the side of the ring beam. The solid element analysis also predicted that the entire thickened portion surrounding SG1 and SG2 undergoes the vertical displacements of magnitudes in the range of $18.4 \mathrm{~mm}-20.2 \mathrm{~mm}$.

\subsubsection{Comparison of the Results for Stresses}

\section{1) Comparison of the Results for Major Principal Stresses}

Murali Mohan et al. [9] have predicted that the entire dome is under major principal stresses in the range of $0.2233 \mathrm{MPa}$ (compressive) - 0.4495 MPa (tensile) with higher values of stress magnitude of 1.587 MPa (tensile) around SG openings. Gandhi et al. (2009) have predicted that the entire dome is under major principal stresses in the range of 1.67 MPa (compressive) - 1.5 MPa (tensile) with a higher value of stress of $2 \mathrm{MPa}$ (tensile) occurring in between two SG openings. In the present study, the entire dome has been observed to be under major principal stress ranging between 11.0 MPa (compressive) and 2.5 MPa (tensile) with the stress magnitude of $0.625 \mathrm{MPa}$ (tensile) occurring between the two SG openings.

\section{2) Comparison of the Results for Minor Principal Stresses}

Murali Mohan et al. [9] have reported that the entire dome is under minor principal stresses in the range of $0.002 \mathrm{MPa}$ (tensile) - 27.61 MPa (compressive). Gandhi et al. [10] have reported that the entire dome is under the minor principal stresses in the range of 1.8 MPa (tensile) - 22.2 MPa (compressive) with the occurrence of tensile stress of magnitude $11 \mathrm{MPa}$ occurring in between the two SG openings. In the present study, the minor principal stresses in the dome have been found to be in the range of 4.7 MPa (compressive) - 29.5 MPa (compressive) with observed small tensile stresses of 0.125 MPa occurring between the two SG openings.

\section{3) Comparison of the Results for Von-Mises Stresses}

Murali Mohan et al. [9] have reported that the entire dome is under von-Mises stresses in the range of 1.505 $\mathrm{MPa}$ - 21.09 MPa with the values of 3.682 MPa - 10.21 MPa in the thickened region. Gandhi et al. [10] have observed von-Mises stresses of about 1.5 MPa - 23 MPa with high values of magnitudes $17 \mathrm{MPa}-21 \mathrm{MPa}$ occurring near the loop cables in the dome. In the present study, the von-Mises stresses have been found to be about 5.0 MPa - 7.5 MPa occurring in the thickened and transition regions.

\subsubsection{Comparison of the Results for Interface Regions}

It has been presented in Section 1 of this paper that Murali Mohan et al. [9] have not included the interface regions in their study. Gandhi et al. [10] have reported that the regions $q=285^{\circ}$ to $345^{\circ}$ for SG1 and $p=15^{\circ}$ to $75^{\circ}$ for SG2 should be considered as the critical regions for possible separation between steel plate and adjacent concrete. In the present study, the regions $q=155^{0}$ to $265^{\circ}$ for SG1 and $p=95^{\circ}$ to $210^{\circ}$ for SG2 have been found to be critical from the view point of separation of steel plate and adjacent concrete.

\section{Conclusions}

Based on the findings of the present study and the observations from the comparison with the results of the past two studies on the same PSC IC dome for its condition under initial prestress transfer, following conclusions are arrived at:

- Three dimensional finite element analysis using two dimensional composite planer shell elements, solid elements, planar shell elements, one dimensional bar elements and one dimensional interface elements (e.g. GAP elements) to model the IC dome/ring beam/wall, thickened/transition regions (of IC dome), steel EPs 
(at SG openings), main anchors (of the steel EPs) and the interface zone (between steel EPs and the dome concrete) respectively, of a typical non-axisymmetric prestressed concrete IC structure having large SG openings with steel EPs, is a suitable analysis method to understand the overall structural behavior of the steel-concrete interface at steel EPs of the SG openings due to initial prestress transfer, of this type of IC structures.

- Due to prestress transfer, the IC dome deflection is predominantly vertically downward with predicted maximum vertical displacement of about $24 \mathrm{~mm}$ occurring around the locations where the prestressing ducts are closely spaced. The dome-deformation is mainly axisymmetric in the region near the ring beam; however, the central portion of the dome including and around the SG openings, deforms unsymmetrically. The ring beam deforms predominantly in the vertically downward direction by about $13 \mathrm{~mm}$ with the occurrence of very small (about $1 \mathrm{~mm}$ ) radially inward displacement.

- The response of the IC dome under initial prestress transfer as indicated by the results for stresses, is well within the elastic limit.

- Relatively higher magnitudes of compressive stresses (within the elastic limits) and tensile stresses (close to tensile strength limit of concrete) are observed at the prestressing cable anchorage locations near the ring beam.

- The interface zone adjacent to the vertical embedded plate at each SG opening, is under compression with occurrence of transverse slip over a certain region.

- The interface zone adjacent to the top surface embedded plate at each SG opening, is under tension over a certain region.

\section{Acknowledgements}

The work reported in this paper is an outcome of the research, "Investigation on Performance of Steel-Concrete Interfaces at Penetration Assemblies in the Inner Containment Dome of a Reactor Building," sponsored by the Atomic Energy Regulatory Board, India.

\section{References}

[1] Warudkar, A.S. (1997) Nuclear Power Plant Containment Design: Evolution and Indian Experience. Joint WNO/ OCEDNEA Workshop, Prestress Loss in NPP Containments, Ciraux NPP, Poitiers.

[2] Chakrabarti, S.K., Sai, A.S.R. and Basu, P.C. (1994) Examination of Leakage Aspects Through Concrete Steel Interfaces at and around Containment Penetration Assemblies. Proceedings of the 3rd International Conference on Containment Design and Operation, Toronto, 19-21 October 1994.

[3] Chakrabarti, S.K., Kumar, A. and Basu, P.C. (1997) Leakage through Concrete-Steel Interfaces at and around Containment Penetration Assemblies: Some New Observations. Proceedings of the 2nd International Conference on Advanced Reactor Safety, Orlando, 1-5 June 1997, 1203-1210.

[4] Basu, P.C. and Rajagopalan, N. (1997) Behaviour of Concrete with Reinforcement under Split Tension. Transactions of the 14th International Conference on Structural Mechanics in Reactor Technology, Lyon, 17-22 August 1997.

[5] Chakrabarti, S.K. and Basu, P.C. (1999) Issues Related to Design and Construction of Prestressed Concrete Inner Containment Dome of Reactor Building with Large Openings. Transactions of the 15th International Conference on Structural Mechanics in Reactor Technology, Seoul, 15-20 August 1999.

[6] Chakrabarti, S.K., Chaturvedi, P.K. and Basu, P.C. (2004) Behavior of Steel Plate-Concrete Interface in Tension. The Bridge and Structural Engineer, 34, 39-52.

[7] Chakrabarti, S.K., Chaturvedi, P.K. and Basu, P.C. (2007) Behavior of Steel Plate-Concrete Interface in Shear. Journal of Structural Engineer, 34, 266-276.

[8] Chakrabarti, S.K., Damarla, V.N. and Basu, P.C. (2008) Behavior of Steel Plate-Concrete Interface under Combined Shear and Normal Forces. The Bridge and Structural Engineer, 38, 49-86.

[9] Mohan, K.M., Chakrabarti, S.K., Basu, P.C. and Ghosh, S. (2000) Study of the Linear Behavior of a PSC Containment Dome with Large Openings. Nuclear Engineering and Design, 196, 123-137. http://dx.doi.org/10.1016/S0029-5493(99)00289-7

[10] Gandhi, D., Chakrabarti, S.K. and Basu, P.C. (2009) A Study on the Local Behavior of Steel-Concrete Interfaces at and around Large Openings in the PSC Inner Containment Dome. Nuclear Engineering and Design, 239, 442-454. http://dx.doi.org/10.1016/j.nucengdes.2008.11.018

[11] Desai, A.A. (2002) An Analytical Study to Evaluate the Performance (at Transfer) of Prestressed Concrete Inner Con- 
tainment Dome of the New Generation Nuclear Reactor Containment Structure. M.Tech. Thesis, IIT Kanpur, Kanpur.

[12] Anon (1998) CSA/NASTRAN User’s Manual 1998. Computerized Structural Analysis and Research Corporation, Augora Hills.

[13] Anon (1998) FEMAP User’s Guide (v.5.0 and v.6.0). Enterprise Software Products Inc., Exton. 